\title{
Severe acute postoperative pain self-reported by children after ambulatory surgeries: a cohort study
}

\author{
Dor aguda pós-operatória intensa autorreferida por crianças após cirurgias ambulatoriais: um estudo de coorte
} Dolor postoperatorio agudo severo autoinformado por niños después de cirugías ambulatorias: un estudio de cohorte

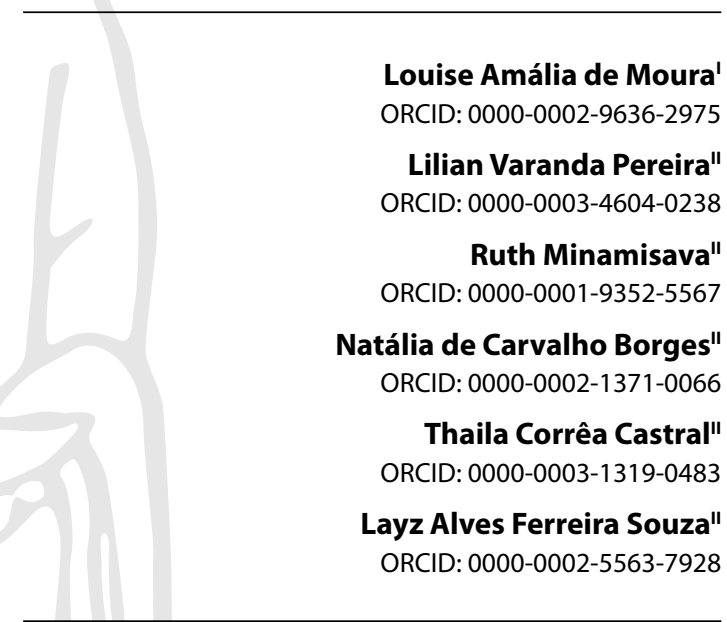

'Instituto Federal de Goiás. Goiânia, Goiás, Brazil. "Universidade Federal de Goiás. Goiânia, Goiás, Brazil.

How to cite this article: Moura LA, Pereira LV, Minamisava R, Borges NC, Castral TC, Souza LAF. Severe acute postoperative pain self-reported by children after ambulatory surgeries: a cohort study. Rev Bras Enferm. 2021;74(Suppl 4):e20200151. https://doi.org/10.1590/0034-7167-2020-0151

Corresponding author: Louise Amália de Moura E-mail: louiseamoura@gmail.com

EDITOR IN CHIEF: Dulce Barbosa ASSOCIATE EDITOR: Priscilla Broca

Submission: $07-15-2020$

Approval: 01-09-2021

\begin{abstract}
Objectives: to estimate the incidence and the risk factors for severe acute postoperative pain self-reported on the first day after hospital discharge. Methods: cohort study with 279 children from both sexes (5-12 years old), indicated for ambulatory surgery in two Brazilian hospitals. Children were assessed at the pre-surgery, immediate postoperative and first postoperative day. Faces Pain Scale-Revised and Yale Preoperative Anxiety Scale Modified were used. Severe postoperative pain was defined as score $\geq 6$. Cox regression analyses were used. Results: the incidence of severe postoperative pain was $15.8 \%(95 \% \mathrm{Cl}: 10.7 \%-20.4 \%)$ on the first postoperative day. Preoperative anxiety ( $\mathrm{HR}=2.23 ; \mathrm{p}=0.049)$, severe preoperative pain $(H R=2.78 ; p=0.031)$ and having undergone two surgical procedures $(H R=2.91 ; p=0.002)$ were associated with severe postoperative pain. Conclusions: the incidence of severe postoperative pain self-reported after hospital discharge was high. Anxiety and severe preoperative pain, in addition to performing two surgical procedures at the same time were confirmed as risk factors.
\end{abstract}

Descriptors: Postoperative Pain; Acute Pain; Child; Ambulatory Surgery; Cohort Studies.

\section{RESUMO}

Objetivos: estimar a incidência e os fatores de risco para dor pós-operatória intensa autorreferida no primeiro dia pós-alta. Métodos: estudo de coorte com 279 crianças de ambos os sexos (5-12 anos), com indicação para cirurgia ambulatorial em dois hospitais brasileiros. As crianças foram avaliadas no pré-operatório, pós-operatório imediato e primeiro dia pós-alta. As Escala de Faces de Dor Revisada e Escala de Ansiedade Pré-operatória de Yale Modificada foram utilizadas. Dor aguda pós-operatória foi definida como pontuação $\geq 6$. Análises de regressão de Cox foram realizadas. Resultados: a incidência de dor pós-operatória foi de 15,8\% (IC95\%: $10,7 \%-20,4 \%)$ no primeiro dia pós-alta. Ansiedade pré-operatória ( $H R=2,23 ; p=0,049)$, dor préoperatória intensa $(\mathrm{HR}=2,78 ; \mathrm{p}=0,031)$ e ter sido submetido a dois procedimentos cirúrgicos $(\mathrm{HR}=2,91 ; \mathrm{p}=0,002)$ foram associados à dor pós-operatória. Conclusões: $a$ incidência de dor intensa autorreferida no pós-operatório foi elevada. Ansiedade, dor pré-operatória intensa e submissão a dois procedimentos cirúrgicos foram confirmados como fatores de risco. Descritores: Dor Pós-Operatória; Dor Aguda; Criança; Cirurgia Ambulatorial; Estudos Longitudinais.

\section{RESUMEN}

Objetivos: estimar la incidencia y los factores de riesgo de dolor postoperatorio agudo severo autoinformado el primer día después del alta hospitalaria. Métodos: estudio de cohorte con 279 niños de ambos sexos, 5-12 años, indicados para cirugía ambulatoria en dos hospitales brasileños, evaluados en el preoperatorio, inmediato y el primer día posoperatorio. Se utilizaron: Faces Pain Scale-Revised y Modified Yale Preoperative Anxiety Scale. Dolor posoperatorio agudo fue una puntuación $\geq 6$. Se utilizó el análisis de regresión de Cox. Resultados: la incidencia de dolor postoperatorio agudo fue del 15,8\% (IC 95\%: $10,7 \%-20,4 \%)$ en el primer día postoperatorio. Ansiedad preoperatoria ( $H R=2,23 ; p=0,049)$, dolor preoperatorio agudo $(\mathrm{HR}=2,78 ; \mathrm{p}=0,031)$ y haber sido sometido a dos procedimientos quirúrgicos $(\mathrm{HR}=2,91 ; \mathrm{p}=0,002)$ se asociaron con dolor postoperatorio agudo. Conclusiones: la incidencia de dolor agudo autoinformado en el postoperatorio después del alta hospitalaria fue alta. Ansiedad, dolor preoperatorio agudo y haber realizado dos intervenciones quirúrgicas al mismo tiempo fueron factores de riesgo.

Descriptores: Dolor Postoperatorio; Dolor Agudo; Niño; Procedimientos Quirúrgicos Ambulatorios; Estudios Longitudinales. 


\section{INTRODUCTION}

Children often experience severe postoperative pain after hospital discharge despite the many advantages offered to patients in pediatric ambulatory surgery. Studies have shown that children undergoing ambulatory surgeries are evaluated with severe pain in their first day at home ${ }^{(1-3)}$. The pain persisted for up to two weeks after surgery in some instances ${ }^{(2-3)}$.

The inadequate management of postoperative pain negatively affects children's health ${ }^{(1)}$. Early exposure to pain has been associated with negative behavioral manifestations $s^{(4)}$ and the risk of patients presenting persistent postoperative pain for periods that go beyond wound healing ${ }^{(5)}$. A relevant fact is the consistent association between postoperative pain severity and chronic post-surgical pain in children ${ }^{(6)}$.

Although the practice of ambulatory surgeries has advanced in recent years, studies about factors associated with postoperative pain in children after hospital discharge remain scarce in the literature. Evidence on risk factors for postoperative pain in children undergoing surgery are associated with $\operatorname{sex}^{(7)}$, anxiety ${ }^{(7)}$, and the surgical technique ${ }^{(4)}$.

A study has shown that children who experience anxiety before a range of surgeries are at risk for experiencing severe postoperative pain ${ }^{(7)}$. Preoperative pain is another well-known risk factor for postoperative pain in the adult population ${ }^{(8)}$. A background study conducted with adolescents undergoing scoliosis surgery has shown that preoperative pain was the best predictor of postoperative pain intensity ${ }^{(9)}$. However, evidence of this association in children undergoing elective ambulatory surgery has not yet been confirmed. This gap in the current literature requires further investigation, especially considering the growing practice of ambulatory surgery and the consequent responsibility of parents for children's pain management at home ${ }^{(10)}$.

\section{OBJECTIVES}

To estimate the incidence and the risk factors for severe acute postoperative pain self-reported on the first day after hospital discharge.

\section{METHODS}

\section{Ethical aspects}

The study was approved by the Research Ethics Committee of Hospital das Clínicas of the Federal University of Goiás and of Hospital Santa Casa de Goiânia. The ethical requirements of Resolution 466/2012 were followed. The consent and assent documents were obtained from parents and children, respectively. All children were instructed on participation in the study or not regardless of their parents' consent.

\section{Study design, location and period}

This prospective cohort study was guided by the STROBE Statement. It was conducted with children undergoing outpatient surgeries from April 2013 to February 2014 in the city of Goiania $(\sim 1,300,000$ inhabitants in 2010), located in the Central-West Brazil. The surgeries were performed in two hospitals. The first hospital treats children from the Brazilian National Health Service (Brazilian SUS - public service) and also from private health insurance, whereas the second hospital only treats users of the Brazilian National Health Service.

\section{Sample and inclusion and exclusion criteria}

A convenience sample of 279 children aged $5-12$ years, who presented physical status $\leq \mathrm{Il}$, based on the Physical Status Classification System of the American Society of Anesthesiologists (ASA) - (i.e. healthy patients or patients with mild systemic disease), undergoing elective ambulatory surgery (surgical duration of up to two hours and shorter hospital stay than 24 hours) were included. Children unable to understand the assessment instruments or diagnosed with cognitive impairment were excluded.

\section{Study protocol}

Children were assessed at three different times:

(T1): Pre-surgical assessment - at surgery day: two trained nurses face-to-face interviewed all children in the waiting room of the two selected hospitals. Socioeconomic and clinical information was provided by children's parents and, whenever necessary, data were collected from patients' medical records. Anxiety symptoms were assessed based on the Yale Preoperative Anxiety Scale Modified (m-YPAS). The scale was applied to patients inside the preoperative waiting room of the surgical center before the anesthetic induction time. The observer inside the preoperative waiting room wore common clothing in order to avoid white coat anxiety. The Faces Pain Scale - revised (FPS-R) was used to assess the intensity of pain at the site where the surgery was going to be performed. Parents and children received verbal guidance on the use of the FPS-R, which was presented in the form of a picture printed on a $21.0 \times 29.7 \mathrm{~cm}$ sheet. Children were instructed on how to indicate pain through the faces represented on the scale, if necessary. The first face on the left was explained as "no pain" and the last face on the right "very much pain". The other faces were explained as other amounts of pain. A copy of the face pain scale was made available to parents for assessment of children's pain after hospital discharge.

(T2): Post-surgical assessment - immediate postoperative period: before their pain level was assessed in a face-to-face interview, children were taken to the Post Anesthesia Care Unit (PACU). They were allowed to spontaneously return from anesthesia until they reached the same level of consciousness presented in the preoperative period. The pain assessment tool (FPS-R) was reviewed with children and their doubts were clarified. Before hospital discharge, the surgeon provided standardized instructions about analgesia for children's parents for the management of postoperative pain at home. Instructions concerned the oral administration of dipyrone whenever necessary, based on the child's body weight $(0.05 \mathrm{ml} / \mathrm{kg})$.

(T3): Post-surgical assessment -at the first postoperative day: pain assessment at home was performed through telephone calls. Children were asked to assess the worst moment of their pain at the surgical site, based on the FPS-R scale. Parents were 
asked whether any analgesics had been administered at home. Children were asked about the relief of their pain.

The measuring instruments adopted in the current study comprised:

Faces Pain Scale - revised (FPS-R) ${ }^{(11)}$ : a self-reported pain intensity measurement tool. The FPS-R is a six-point scale with pictures of faces indicating pain intensities ranging from "no pain" to "very much pain". A numeric value from 0 to 10 based on scores 0-2-4-6-8-10 was attributed to each face. Based on previous research, clinically severe pain was defined as FPS-R $\geq$ $6^{(3)}$. The FPS-R version translated into Brazilian Portuguese was used in the current study ${ }^{(11)}$. All children were trained in how to complete the FPS-R scale at T1 and T2.

Yale Preoperative Anxiety Scale Modified (m-YPAS) ${ }^{(12)}$ : this structured observation measurement tool is used to assess anxiety in children. The cross-cultural adaptation and validation for Brazilian Portuguese that was used in the current study has evidenced reliability of its psychometrics properties, which was assessed based on Cronbach's alpha coefficient (0.88-0.95), as well as on Spearman's (0.44-0.95), Kappa (0.79-1.00) and Guttman's correlation coefficients $(0.63-0.90)^{(12)}$. The scale was used in the waiting room of the surgical center, during the immediate preoperative period and until before induction of anesthesia. Preoperative anxiety was considered present when the total m-YPAS score $>30^{(4)}$.

Brazilian Economic Classification Criteria (BECC) ${ }^{(13)}$ : evaluation based on this instrument takes into consideration the sum of the householder schooling level and all equipment functioning properly in the household. The socioeconomic stratum (SES) was classified as levels A1 (42-46), A2 (35-41), B1 (29-34), B2 (23-28), C1 (18-22), C2 (14-17), D (8-13) and E (0-7). BECC strata A1, A2, $B 1$ and $B 2$ were categorized as $A-B$, whereas strata $C 1, C 2, D$ and E were categorized as C-D-E.

\section{Surgical, anesthetic and analgesic procedures}

All children underwent standardized surgical, anesthetic and analgesic procedures adopted by the hospital in the intraoperative period. Information related to the surgical procedure was collected from the patient's medical record. Most (84.9\%) children underwent general inhalation anesthesia with halothane. Prior to the initial surgical incision, $98.9 \%$ of patients received $0.5 \%$ bupivacaine infiltration (with vasoconstrictor) at the surgical site (mean $=25.3 \mathrm{mg}, \mathrm{SD}=8.5$ ). Additional analgesia with dipyrone (89.2\%) was intramuscularly administered. The mean dipyrone dose was calculated based on children's weight $(25 \mathrm{mg} / \mathrm{kg})$. Most $(90.0 \%)$ children underwent a single surgical procedure, whereas the remaining (10\%) underwent two procedures at the same surgical time.

\section{Statistical data analysis}

Baseline features subjected to statistical analysis were described as figures and proportions, whereas mean age and standard deviation were expressed in years. Pain and anxiety scores were reported as medians and interquartile ranges (IQR). The incidence of postoperative pain and its respective confidence interval $(95 \%$ $\mathrm{Cl}$ ) were calculated by dividing the number of children with severe postoperative pain by the total number of recruited children. Severe acute postoperative pain was defined as the FPS-R score $\geq 6^{(11)}$. Crude and adjusted Cox regression analysis was used to identify the risk factors based on severe pain at the first postoperative day as the outcome variable. Exposure variables were sex $(0=$ male; $1=$ female); age (in years); socioeconomic strata ( $0=A-B ; 1=C-D-E)$; previous hospitalization $(0=$ no; $1=y e s)$; previous surgery $(0=$ no; $1=y e s) ;$ preoperative pain ( $0=$ no; $1=y e s) ;$ preoperative anxiety $(0=$ no; $1=y e s)$; surgery type; and two surgical procedures ( $0=$ no; $1=y e s)$. Only exposure variables presenting $p$-value $\leq 0.10$ in the crude analysis were included in the multiple analyses in the backward stage. Participants whose data were missing were excluded from the model. P-values $\leq 0.05$ were considered statistically significant. SPSS software v.18.0 was used in all analyses.

\section{RESULTS}

Three hundred and six children (306) were referred to ambulatory surgeries during the studied period. Twenty-one of them were not eligible (eight needed to stay in the hospital for more than 24 hours and 13 did not understand the assessment instruments) and six refused to participate in the study. Thus, the final cohort comprised 279 children.

\section{Baseline characteristics}

Table 1 shows children's baseline characteristics. The prevalence of self-reported severe preoperative pain was 9\% (95\% Cl: 5.7\%$12.2 \%)$ and $79.5 \%$ (95\%Cl: $74.0 \%-84.6 \%)$ of children presented preoperative anxiety.

Table 1 - Baseline characteristics of the investigated children $(\mathrm{N}=279)$, Goiânia, Brazil, 2014

\begin{tabular}{lccc}
\hline Characteristics & $\mathbf{n}(\%)$ & $\begin{array}{c}\text { Mean (SD): } \\
\text { Min- Max }\end{array}$ & $\begin{array}{c}\text { Median (IQR): } \\
\text { Min- Max }\end{array}$ \\
\hline Age in years & & $7.5(2.1): 5-12$ & \\
Female sex & $107(38.3)$ & & \\
Socioeconomic stratum & & & \\
A-B & $86(30.8)$ & \\
$\quad$ C-D-E & $193(69.2)$ & $23.4-68.4$ \\
Previous hospitalization & $139(49.8)$ & \\
Previous surgery & $46(16.5)$ & \\
Preoperative anxiety & $202(79.8)$ & \\
(m-YPAS) & & \\
Preoperative pain intensity & & \\
(FPS-R) & $15(60.0)$ & \\
$\quad$ FPS-R<6 & $10(40.0)$ & \\
FPS-R 6 & $28(10.0)$ & \\
Two surgical procedures & & \\
Surgery type* & & \\
Inguinal hernia repair & $124(49.4)$ & \\
Umbilical hernia repair & $61(24.3)$ & \\
Circumcision & $32(12.8)$ & \\
Epigastric hernia repair & $23(9.1)$ & \\
Orchidopexy & $6(2.4)$ & \\
Hypospadias & $2(0.8)$ & \\
Anal fistulectomy & $2(0.8)$ & \\
Femoral hernia repair & $1(0.4)$ & \\
\hline
\end{tabular}

Note: $I Q R=$ Interquartile Ranges. $m$-YPAS $=$ Yale Preoperative Anxiety Scale Modified. FPS- $R=$ Faces Pain Scale - revised. Min $=$ Minimum. Max $=$ Maximum. ${ }^{*}$ missing $=26 .{ }^{* *} n$-total $=251$ (number of surgeries without two surgical procedures). 


\section{Incidence of severe acute postoperative pain self-reported}

The incidence of severe acute postoperative pain on the first day after hospital discharge (T3) was 15.8\% (95\%Cl: 10.7\%-20.4\%). Among children who reported postoperative pain on the first postoperative day, $62.2 \%$ received analgesics provided by their parents. Most (93.4\%) children reported pain relief after analgesics intake.

\section{Risk factors predictors of severe postoperative pain}

Table 2 shows potential independent risk factors of severe postoperative pain. After multivariate adjustment, children who presented preoperative anxiety, reported severe preoperative pain, and children who underwent two surgical procedures were at a higher risk for reporting severe postoperative pain on the first postoperative day (Table 3).

Table 2 - Potential risk factors for severe acute postoperative pain in children on the first day after hospital discharge, Goiânia, Brazil, 2014

\begin{tabular}{|c|c|c|c|c|}
\hline \multirow{2}{*}{ Factors } & \multicolumn{3}{|c|}{$\begin{array}{l}\text { Severe Acute Postoperative } \\
\text { Pain on the } 1^{\text {st }} \text { Day }\end{array}$} & \multirow{2}{*}{$p$ value } \\
\hline & $\boldsymbol{\beta}$ & HR & $\mathrm{Cl}(95 \%)$ & \\
\hline Female sex & 0.35 & 1.42 & $0.87-2.30$ & 0.152 \\
\hline Age, mean (SD) & -0.00 & 0.99 & $0.89-1.11$ & 0.975 \\
\hline C-D-E socioeconomic stratum & 0.47 & 1.60 & $0.88-2.88$ & 0.119 \\
\hline Previous hospitalization & 0.25 & 1.28 & $0.79-2.08$ & 0.312 \\
\hline Previous surgery & -0.10 & 0.90 & $0.46-1.77$ & 0.770 \\
\hline Preoperative anxiety & 0.62 & 1.87 & $0.89-4.13$ & 0.101 \\
\hline Severe preoperative pain & 0.79 & 2.20 & $0.88-5.48$ & 0.089 \\
\hline Two surgical procedures & 0.68 & 1.99 & $1.06-3.72$ & 0.031 \\
\hline \multicolumn{5}{|l|}{ Surgery type ${ }^{*}$} \\
\hline Inguinal hernia repair & 0.14 & 1.15 & $0.70-1.88$ & 0.564 \\
\hline Umbilical hernia repair & 0.05 & 1.05 & $0.59-1.86$ & 0.865 \\
\hline Epigastric hernia repair & 0.27 & 1.32 & $0.60-2.89$ & 0.487 \\
\hline Circumcision & 0.69 & 2.00 & $0.73-5.52$ & 0.177 \\
\hline Orchidopexy & 0.35 & 1.42 & $0.19-10.29$ & 0.723 \\
\hline
\end{tabular}

Note: $\beta=$ Regression coefficient. $S D=$ Standard Deviation. $H R=$ Hazard Ratio. $\mathrm{Cl}(95 \%)=95 \%$ Confidence Interval. *Hypospadias, Anal fistulectomy and Femoral hernia repair were not included in the model given the low number of cases.

Table 3 - Risk factors for severe acute postoperative pain in children, Goiânia, Brazil, 2014

\begin{tabular}{lcccc}
\hline Risk factors & $\boldsymbol{\beta}$ & $\mathbf{H R}^{*}$ & $\mathbf{C l}(\mathbf{9 5 \% )}$ & $\boldsymbol{p}$ value \\
\hline Preoperative anxiety & 0.80 & 2.23 & $1.00-4.94$ & 0.049 \\
Severe preoperative pain & 1.02 & 2.78 & $1.09-7.03$ & 0.031 \\
Two surgical procedures & 1.06 & 2.91 & $1.46-5.77$ & 0.002 \\
\hline
\end{tabular}

Note: $\beta=$ Regression coefficient. ${ }^{*} \mathrm{HR}=$ Hazard Ratio adjusted to sex. $\mathrm{Cl}(95 \%)=95 \%$ Confidence Interval.

\section{DISCUSSION}

One out of six children undergoing ambulatory surgery in the current study reported severe pain on the first day after hospital discharge. Additionally, the study produced evidence on the risk factors for severe postoperative pain such as preoperative anxiety, preoperative pain and two surgical procedures performed at the same time in children undergoing ambulatory surgery. To the best of our knowledge, this is the first study focused on investigating the incidence and risk factors for severe acute postoperative pain in Brazilian children undergoing ambulatory surgery.

In this study, the first contact with children at home was in up to 36 postoperative hours, showing that the current findings reflect the critical behavior of pain on the first day after surgery. In hospitals where the surgeries were performed, there was no protocol for analgesia and individualized care for children with pain, which may have influenced the rate of severe pain in the sample studied. However, the incidence was lower than the findings of other studies ( $51 \%$ to $61 \%$ ) that investigated children with clinically significant pain (score $\geq 6$ ) on the first postoperative day, despite the provision of analgesic doses at home ${ }^{(1,14)}$.

This wide variation in the incidence of severe acute postoperative pain after hospital discharge may be explained by differences in pain intensity measurement instruments, type of surgery performed and parents' evaluation of pain (using the Parent Postoperative Pain Measure (PPPM), unlike the present study, where assessment was through children's self-report. Evidence of significant pain in children undergoing tonsillectomy (PPPM $\geq$ 6), which persists at least one week postoperatively, has been drawn up, which did not happen in cases of orchidopexy and inguinal hernia repair ${ }^{(2)}$. These studies ${ }^{(1-2,14)}$ did not mention the type of anesthesia and intraoperative analgesia used.

Additionally, the use of multimodal therapy, including regional anesthesia, used in the present study and recommended for the management of postoperative pediatric pain ${ }^{(15)}$ may not have been used in all searches. Like the use of dipyrone, administered intramuscularly in this study, despite the favorable evidence supporting its use intravenously in the intraoperative period of pediatric surgery ${ }^{(16)}$. We encourage standardized and detailed written recommendations for pain management at home, especially with regard to the use of analgesics, since the perception of parents may be different in different cultures, for example, in Latin families of low socioeconomic level, where parents' perception of analgesics seems to influence pain management at home ${ }^{(1)}$.

Evidence on risk factors for postoperative pain in children undergoing outpatient surgeries remain scarce, mainly in cases of clinically severe pain intensity ${ }^{(1,14)}$. Preoperative pain has been clearly identified as a postoperative pain predictor in the adult population $^{(8)}$, but the current study is the first to point out its predictive value for acute pain in children undergoing ambulatory surgery. A study involving adolescents undergoing large surgeries has shown the effect of preoperative pain on postoperative pain intensity ${ }^{(9)}$. Based on a systematic review, there was association between preoperative pain intensity and chronic postoperative pain ${ }^{(17)}$. In fact, pain itself is the factor most consistently associated with future pain issues ${ }^{(18)}$.

Our findings revealed an association between severe pain in the postoperative period and the presence of anxiety before surgery in children. In a study, was found a correlation between preoperative anxiety and postoperative pain in a range of elective surgeries ${ }^{(7)}$. Major sensitivity to anxiety was correlated with greater perception of pain intensity after pediatric outpatient surgery ${ }^{(19)}$. Anxiety before surgery can be influenced by age ${ }^{(20)}$. Nevertheless, the control of preoperative anxiety by preoperative programs, as the preoperative immersive virtual reality tour ${ }^{(21)}$ 
can be effective to manage postoperative pain as suggested by another randomized controlled study ${ }^{(22)}$.

Our results showed association between two surgical procedures performed at the same time and severe postoperative pain. Based on our knowledge, this association has not been the focus of any other study so far; therefore, the current study is pioneer in this approach. We believe that two surgical procedures involve greater manipulation, larger and longer surgeries and, consequently, higher pain intensity scores. This happens because the possible exacerbation of the acute inflammatory phase increases the local tissue response due to peripheral sensitization, a phenomenon that is directly associated with the extent of cell damage, as well as with stimulus intensity and duration ${ }^{(18)}$. Additional studies are necessary to better understand the role played by the number of surgical procedures performed during the same surgery and the pain perception.

\section{Study limitations}

The current study had limitations; a convenience sample was used, and the inclusion of different surgery types can result in different perioperative experiences. Another limitation could be the lack of information about analgesic doses and class used at home, although medical prescriptions predominantly consisted of simple analgesics such as dipyrone.

\section{Contributions to nursing, health or public policies}

The current findings extend the understanding about the influence of risk factors on severe acute postoperative pain reports in children. These findings highlight the relevance of pain assessment in a biopsychological approach, pointing to the direction of planning nursing interventions aimed at individualized care of the painful experience. Hospital discharge performed by the nurse must include instructions for pain management, as well as referral to a primary care nurse in order to ensure follow-up in the postoperative period. Family health services can assist the child at home. Future research should be performed with focus on investigating the effect of severe acute postoperative pain on the development of chronic postoperative pain in children undergoing ambulatory surgeries.

\section{CONCLUSION}

This study confirms the need to improve postoperative pain management after hospital discharge of children undergoing ambulatory surgery. The report of severe acute postoperative pain was associated with preoperative anxiety, preoperative pain and two surgical procedures performed at the same time. These findings support early treatment (before surgery) for children at risk for developing severe postoperative pain after hospital discharge.

\section{REFERENCES}

1. Rosales A, Fortier MA, Campos B, Kain ZN. Postoperative pain management in Latino families: parent beliefs about analgesics predict analgesic doses provided to children. Pediatr Anesth. 2016;26(3):307-14. https://doi.org/10.1111/pan.12846

2. Stewart DW, Ragg PG, Sheppard S, Chalkiadis GA. The severity and duration of postoperative pain and analgesia requirements in children after tonsillectomy, orchidopexy, or inguinal hernia repair. Pediatr Anesth. 2012;22(2):136-43. https://doi. org/10.1111/j.1460-9592.2011.03713.x

3. Brown R, Fortier MA, Zolghadr S, Gulur P, Jenkins BN, Kain ZN. Postoperative Pain Management in Children of Hispanic Origin. Anesth Analg. 2016;122(2):497-502. https://doi.org/10.1213/ANE.0000000000001042

4. Zavras N, Tsamoudaki S, Ntomi V, Yiannopoulos I, Christianakis E, Pikoulis E. Predictive factors of postoperative pain and postoperative anxiety in children undergoing elective circumcision: a prospective cohort study. Korean J Pain. 2015;28(4):244. https://doi.org/10.3344/kjp.2015.28.4.244

5. Mossetti V, Boretsky K, Astuto M, Locatelli BG, Zurakowski D, Lio R, et al. Persistent pain following common outpatient surgeries in children: a multicenter study in Italy. Pediatr Anesth. 2018;28(3):231-6. https://doi.org/10.1111/pan.13321

6. Batoz H, Semjen F, Bordes-Demolis M, Bénard A, Nouette-Gaulain K. Chronic postsurgical pain in children: prevalence and risk factors: a prospective observational study. Br J Anaesth. 2016;117(4):489-96. https://doi.org/10.1093/bja/aew260

7. Chieng YJS, Chan WCS, Liam JLW, Klainin-Yobas P, Wang W, He H-G. Exploring influencing factors of postoperative pain in school-age children undergoing elective surgery. J Spec Pediatr Nurs. 2013;18(3):243-52. https://doi.org/10.1111/jspn.12030

8. Gerbershagen HJ, Pogatzki-Zahn E, Aduckathil S, Peelen LM, Kappen TH, van Wijck AJM, et al. Procedure-specific risk factor analysis for the development of severe postoperative pain. Anesthesiol. 2014;120(5):1237-45. https://doi.org/10.1097/ALN.0000000000000108

9. Ferland CE, Saran N, Valois T, Bote S, Chorney JM, Stone LS, et al. Preoperative distress factors predicting postoperative pain in adolescents undergoing surgery: a preliminary study. J Pediatr Health Care. 2017;31(1):5-15. https://doi.org/10.1016/j.pedhc.2015.12.008

10. Heikal S, Bowen L, Thomas M. Paediatric day-case surgery. Anaesth Intensive Care Med. 2019;20(6):318-23. https://doi.org/10.1016/j. mpaic.2019.03.005

11. Charry CLE, Piola JS, Linhares MBM, Silva JA. Validity and reliability assessment of the Brazilian version of the Faces Pain Scale-Revised. Psychol Neurosci. 2014;7(1):55-9. https://doi.org/10.3922/j.psns.2014.1.08

12. Guaratini AA. Estudo da ansiedade pré-operatória de Yale Modificada: tradução, estudo da confiabilidade e utilização em crianças de 02 a 07 anos. Fundação Arnaldo Vieira de Carvalho. Faculdade de Ciências Médicas da Santa Casa de São Paulo. Curso de Pós-Graduação. Stricto Sensu. Resumos - Teses defendidas (2006) - Parte 2. Arq Med Hosp Fac Cienc Med Santa Casa São Paulo [Internet]. 2007;52(2):59. [cited 2019 Nov 04]. Available from: http://arquivosmedicos.fcmsantacasasp.edu.br/index.php/AMSCSP/article/view/453/510 
13. Associação Brasileira de Empresas de Pesquisa. Critério de Classificação Econômica Brasileira[Internet]. 2012 [cited 2019 Nov 04]. Available from: http://www.abep.org/criterio-brasil

14. Rony RYZ, Fortier MA, Chorney JM, Perret D, Kain ZN. Parental postoperative pain management: attitudes, assessment, and management. Pediatrics. 2010;125(6):e1372-8. https://doi.org/10.1542/peds.2009-2632

15. Practice Guidelines for Acute Pain Management in the Perioperative Setting: an updated report by the american society of anesthesiologists task force on acute pain management. Anesthesiol. 2012;116(2):248-73. https://doi.org/10.1097/ALN.0b013e31823c1030

16. Witschi L, Reist L, Stammschulte T, Erlenwein J, Becke K, Stamer U. Perioperative use of metamizole and other non-opioid analgesics in children: results of a survey. Anaesthesist. 2019;68(3):152-60. German. https://doi.org/10.1007/s00101-018-0532-4

17. Rabbitts JA, Fisher E, Rosenbloom BN, Palermo TM. Prevalence and predictors of chronic postsurgical pain in children: a systematic review and meta-analysis. J Pain. 2017;18(6):605-14. https://doi.org/10.1016/j.jpain.2017.03.007

18. Chapman CR, Vierck CJ. The transition of acute postoperative pain to chronic pain: an integrative overview of research on mechanisms. J Pain. 2017;18(4):359.e1-359.e38. https://doi.org/10.1016/j.jpain.2016.11.004

19. Esteve R, Marquina-Aponte V, Ramírez-Maestre C. Postoperative pain in children: association between anxiety sensitivity, pain catastrophizing, and female caregivers' responses to children's pain. J Pain. 2014;15(2):157-68.e1. https://doi.org/10.1016/j.jpain.2013.10.007

20. Moura LA, Dias IM, Pereira LV. Prevalence and factors associated with preoperative anxiety in children aged 5-12 years. Rev Latino-Am Enfermagem. 2016;24:e2708. https://doi.org/10.1590/1518-8345.0723.2708

21. Ryu JH, Oh AY, Yoo HJ, Kim JH, Park JW, Han SH. The effect of an immersive virtual reality tour of the operating theater on emergence delirium in children undergoing general anesthesia: a randomized controlled trial. Paediatr Anaesth. 2019;29(1):98-105. https://doi. org/10.1111/pan.13535

22. Fortier MA, Bunzli E, Walthall J, Olshansky E, Saadat H, Santistevan R, et al. Web-Based tailored intervention for preparation of parents and children for outpatient surgery (WebTIPS). Anesth Analg. 2015;120(4):915-22. https://doi.org/10.1213/ANE.0000000000000632 